\title{
Detection of Pyruvate Metabolism Disorders by Culture of Skin Fibroblasts with Dichloroacetate
}

\author{
ETSUO NAITO, YASUHIRO KURODA, EIJI TAKEDA, ICHIRO YOKOTA, HIDEAKI KOBASHI, \\ AND MASUHIDE MIYAO \\ Department of Pediatrics, School of Medicine, University of Tokushima, Tokushima, Japan
}

\begin{abstract}
For use in screening for disorders of pyruvate metabolism, a sensitive assay method was developed for measuring the rate of decarboxylation of $\left[1-{ }^{14}\right.$ Clpyruvate during in vitro culture of skin fibroblasts with dichloroacetate (DCA). The rate of decarboxylation of $\left[1-{ }^{14} \mathrm{C}\right] p y r u-$ vate by skin fibroblasts from control subjects increased from $59.6 \pm 13.2$ to $97.3 \pm 12.0 \mathrm{nmol} / \mathrm{h} / \mathrm{mg}$ protein during in vitro culture in medium supplemented with $10 \mathrm{mM}$ DCA for 3 days. In contrast, the rate hardly increased in cells from four of 20 patients with congenital lactic acidosis of unknown cause during in vitro culture with DCA. On day 3 of culture, the values for the four patients did not overlap those of control cells and so these four patients could be clearly distinguished from control subjects. Measurements of the original activity and the activity of the pyruvate dehydrogenase (PDH) complex after activation with a broad specificity protein phosphatase and DCA suggested that in three of the patients the aberration was a disorder in the mechanism for activation of PDH, including deficiency of PDH phosphatase or a mutation of PDH itself, whereas that in the fourth patient it might be a disorder of the mitochondrial transport system for pyruvate. Thus, measurement of the rate of decarboxylation of $\left[1-{ }^{14} \mathrm{C}\right]$ pyruvate by skin fibroblasts cultured in medium supplemented with $10 \mathrm{mM}$ DCA for 3 days is a useful method for screening for disorders of pyruvate metabolism in cultured skin fibroblasts. (Pediatr Res 23: 561-564, 1988)
\end{abstract}

\section{Abbreviations}

DCA, dichloroacetate

PDH, pyruvate dehydrogenase

PBS, phosphate-buffered saline

Chronic congenital lactic acidosis of childhood is characterized by persistently high levels of blood pyruvate and lactate. Most patients with this disease die in infancy or show growth and psychomotor retardation because no adequate treatment is available. Recently, the number of reported cases of congenital lactic acidosis has been increasing. Hereditary deficiencies leading to lactic acidosis have been demonstrated in the enzymes of the PDH (EC 1.2.4.1) complex, in the key enzymes of the pathway of gluconeogenesis and in the enzymes of the electron transport system (1). However, in many patients with congenital lactic acidosis, the primary biochemical defect is unknown $(2,3)$.

Received October 26, 1987; accepted January 26, 1988.

Correspondence and requests for reprints Dr. Yasuhiro Kuroda, Department of Pediatrics, School of Medicine, University of Tokushima, 3-Kuramoto-cho, Tokushima 770, Japan.

Supported by Grant-in-Aid for Special Project Research of Inborn Errors of Metabolism from the Ministry of Education, Science and Culture of Japan.
Therefore, we have been trying to develop a sensitive method for screening for disorders of pyruvate metabolism in cultured skin fibroblasts from patients with congenital lactic acidosis. Herein we found that measurement of the rate of decarboxylation of $\left[1-{ }^{14} \mathrm{C}\right]$ pyruvate during in vitro culture of the fibroblasts with DCA, which is an activator of PDH, is a useful screening method for disorders of pyruvate metabolism. We also found that for determination of the cause of PDH deficiency, both the original activity of the PDH complex and also its total activity induced by in vitro activations with a broad specificity protein phophatase and DCA must be determined.

\section{MATERIALS AND METHODS}

Chemicals. $\left[1-{ }^{14} \mathrm{C}\right]$ pyruvate and $\left[1-{ }^{14} \mathrm{C}\right]$ acetate were obtained from Amersham Corp., Ltd. (Oakville, Canada). Sodium DCA was obtained from Tokyo Kogyo (Tokyo, Japan) and the other compounds were from Sigma Chemical Co. (St. Louis, MO).

Cultured fibroblasts. Fibroblasts were grown in minimal essential medium (Nissui, Tokyo, Japan) with $10 \%$ fetal calf serum. Fibroblasts were obtained from skin biopsies of a patient with PDH deficiency, demonstrated in a biopsy specimen of muscle (4), 20 patients with congenital lactic acidosis of unknown cause and four patients who had normal blood levels of lactate. Confluent cells were cultured in minimal essential medium supplemented with $10 \%$ fetal calf serum and 0 to $12.5 \mathrm{mM} \mathrm{DCA}$, for 1 to 4 days and harvested with $0.25 \%$ trypsin. The cells were washed twice with PBS.

Assays of rates of decarboxylation of pyruvate and acetate. The rate of decarboxylation of $\left[1-{ }^{14} \mathrm{C}\right]$ pyruvate was measured by the method of Robinson et al. (2). The rate of decarboxylation of $\left[1-{ }^{14} \mathrm{C}\right]$ acetate was measured by a modification of the method of Blass et al. (5). Briefly, $0.15 \mathrm{ml}$ of cell suspension in PBS was added to $0.05 \mathrm{ml}$ of PBS containing $10 \mathrm{mM}\left[1-{ }^{14} \mathrm{C}\right]$ acetate $(1.5$ $\mathrm{mCi} / \mathrm{mmol}$ ) in a closed vessel and incubated at $37^{\circ} \mathrm{C}$ for $2 \mathrm{~h}$. The reaction was terminated by adding $0.1 \mathrm{ml}$ of $2 \mathrm{~N} \mathrm{HCl}$ containing $0.1 \%$ dinitrophenylhydrazine and ${ }^{14} \mathrm{CO}_{2}$ was trapped on filter paper soaked in $0.1 \mathrm{ml}$ of $10 \% \mathrm{KOH}$ which was placed in a plastic well attached to the rubber stoppers of the vessel. Radioactivity was measured in a liquid scintillation spectrometer (Aloka 612, Tokyo, Japan).

Assays of PDH complex. The original and total activities of the PDH complex were determined by a modification of the method of Toshima et al. $(4,6)$. The harvested cells were suspended in $0.1 \mathrm{ml}$ of ice-cold homogenizing buffer (7), and the cell suspension was rapidly frozen and stored at $-70^{\circ} \mathrm{C}$ for $24 \mathrm{~h}$. For assay, the cell suspension was thawed and homogenized in a glass-Teflon homogenizer. The original activity of the $\mathrm{PDH}$ complex was determined by measuring the evolution of ${ }^{14} \mathrm{CO}_{2}$ from $\left[1-{ }^{14} \mathrm{C}\right]$ pyruvate. The assay mixture at $\mathrm{pH} 7.5$ in a final volume of $0.25 \mathrm{ml}$ consisted of $30 \mathrm{mM}$ potassium phosphate, $2.5 \mathrm{mM}$ NAD, $0.8 \mathrm{mM}$ CoA, $0.4 \mathrm{mM}$ cocarboxylase, $2 \mathrm{mM}$ dithiothreitol, $2 \mathrm{mM} \mathrm{MgCl}_{2}, 0.01 \%$ Triton X-100, $2 \mathrm{mM}\left[1-{ }^{14} \mathrm{C}\right]$ 
pyruvate $(0.1 \mathrm{mCi} / \mathrm{mmol})$, and $0.1 \mathrm{ml}$ of homogenate. For determination of the total activity, the homogenate was preincubated with partially purified preparation of a broad specificity protein phosphatase from rabbit liver (8), and $3.7 \mathrm{mM} \mathrm{MnCl}$ for $30 \mathrm{~min}$ at $37^{\circ} \mathrm{C}$, and then the activity was measured as described above.

The DCA-activated activity of the PDH complex was measured by a modification of the method of Sheu et al. (9). The harvested cells were incubated for $15 \mathrm{~min}$ at $37^{\circ} \mathrm{C}$ in PBS containing $5 \mathrm{mM}$ DCA to activate PDH. The incubation was stopped by adding ice-cold homogenizing buffer, and the suspension was then frozen rapidly and stored at $-70^{\circ} \mathrm{C}$ for $24 \mathrm{~h}$. For assay, the cell suspension was thawed in ice and homogenized, and then the activity was determined as described above. Protein was measured by the method of Lowry et al. (10).

Brief case reports of four patients (Tables 1-3). Case 1, a 10month-old boy, had mental and developmental retardation, muscle hypotonia, and seizures. He was delivered at 38 wk by cesarean section because his mother suffered from severe toxemia of pregnancy. He weighed $1819 \mathrm{~g}$ and showed asphyxia at birth. His development was markedly retarded. At the age of 10 months, unconsciousness, left hemiparesis, and lactic acidosis developed after upper respiratory infection. Computed tomography revealed low density in the right hemisphere. Case 2, a 9yr-old girl, had mental and developmental retardation and psychomotor seizures. She was born after an uncomplicated pregnancy but her development was gradually retarded. Psychomotor seizures developed at the age of $6 \mathrm{yr}$ and she was found to have lactic acidosis at the age of 9 yr. Case 3, a 10-yr-old boy, had muscle hypotonia, ataxic gait, and mental retardation. He was born after $40 \mathrm{wk}$ of gestation. He weighed $3080 \mathrm{~g}$ and showed severe asphyxia at birth. His development was retarded. At the age of 7 months, his spontaneous activity decreased and he easily choked on milk. At the age of $1 \mathrm{yr}$, muscle hypotonia, nystagmus, and dysphagia developed and he was found to have lactic acidosis. He was considered to have Leigh's disease because computed tomography revealed low density in the bilateral putamen and hypothalamus. Case 4, a 5-month-old boy, had mental and developmental retardation, muscle hypotonia, and seizures. At the age of 5 months, he was found to have lactic acidosis and considered to have Leigh's disease because computed tomography revealed low density in the bilateral basal ganglia.

\section{RESULTS}

As shown in Figure 1, the rate of decarboxylation of $\left[1-{ }^{14} \mathrm{C}\right]$ pyruvate by skin fibroblasts from control subjects increased during in vitro culture with various concentrations of DCA for 3 days and was maximal with $10 \mathrm{mM}$ DCA. The rate of decarboxylation of $\left[1-{ }^{14} \mathrm{C}\right]$ pyruvate by skin fibroblasts from control subjects increased from day 1 of their in vitro culture in medium supplemented with $10 \%$ fetal calf serum and $10 \mathrm{mM} \mathrm{DCA}$ and reached a maximum on day 3 (Fig. 2).

The rates of decarboxylation of $\left[1-{ }^{14} \mathrm{C}\right]$ pyruvate by skin fibroblasts from four control subjects, 20 patients with congenital lactic acidosis of unknown cause, and one patient with PDH deficiency were measured. As shown in Table 1 , in fibroblasts from four of 20 patients with congenital lactic acidosis the rates were significantly lower than those in control fibroblasts, but the upper values in these patients overlapped the lower values for control subjects. During in vitro culture with $10 \mathrm{mM}$ DCA for 3 days, the rate of decarboxylation of $\left[1-{ }^{14} \mathrm{C}\right]$ pyruvate by control cells increased markedly. In contrast, during culture with DCA the rates of decarboxylation by cells from a patient with PDH deficiency and from four patients with congenital lactic acidosis of unknown cause scarcely increased and the values for the four patients did not overlap those of control cells.

Table 2 shows the activities of the PDH complex in cultured skin fibroblasts assayed in various conditions. In control cells, the DCA-activated activities of the PDH complex were similar

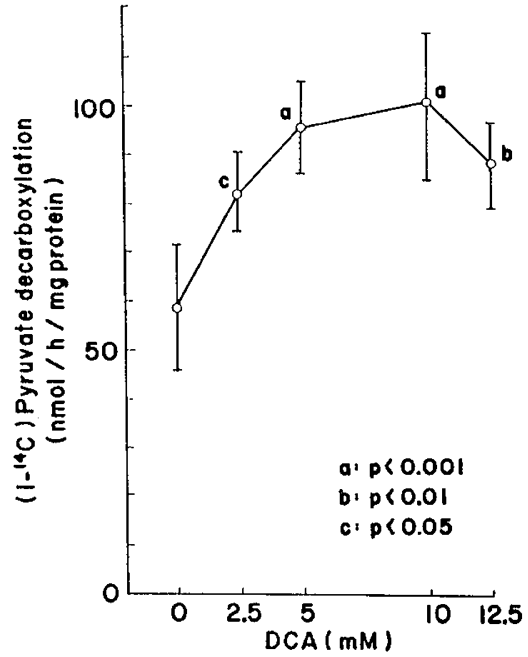

Fig. 1. Effect of DCA on the rates of decarboxylation of $\left[1-{ }^{14} \mathrm{C}\right]$ pyruvate in cultured skin fibroblasts from control subjects. To determine the optimum concentration in culture medium, skin fibroblasts from control subjects were cultured with various concentrations of DCA for 3 days.

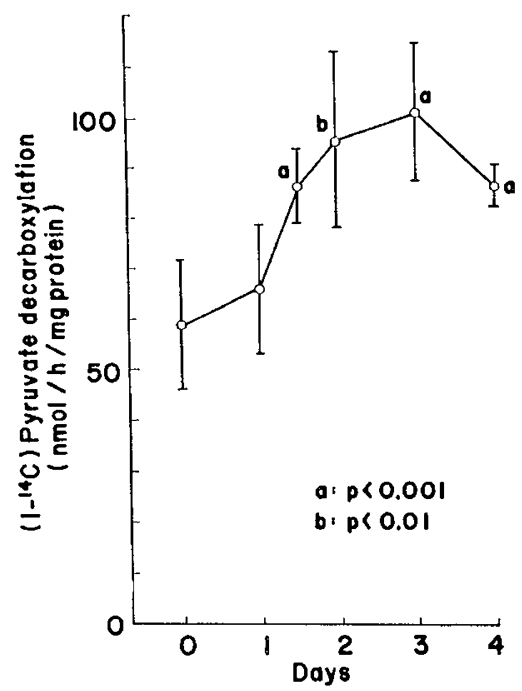

Fig. 2. Changes of the rates of decarboxylation of $\left[1-{ }^{14} \mathrm{C}\right]$ pyruvate in skin fibroblasts from control subjects during in vitro culture with $10 \mathrm{mM}$ DCA.

Table 1. Effect of DCA on rates of decarboxylation of $\left[1-{ }^{14} C\right]$ pyruvate in cultured skin fibroblasts from control subjects, patients with congenital lactic acidosis of unknown cause, and patient with $P D H$ deficiency (mean $\pm S D)$

\begin{tabular}{lll}
\hline & \multicolumn{2}{c}{$\begin{array}{c}\text { Pyruvate decarboxylation } \\
\text { (nmol/h/mg protein) }\end{array}$} \\
\cline { 2 - 3 } & Without DCA & With 10 mM DCA \\
\hline PDH deficiency (1) & $10.9 \pm 4.1(5)^{*}$ & $11.1 \pm 6.0(4)^{*}$ \\
Lactic acidosis (20) & & \\
Low pyruvate oxidation (4) & & \\
$\quad$ Case 1 & $40.2 \pm 8.6(7) \dagger$ & $42.7 \pm 11.6(9)^{*}$ \\
Case 2 & $30.8 \pm 3.3(3) \dagger$ & $36.7 \pm 6.3(4)^{*}$ \\
Case 3 & $39.3 \pm 3.4(3) \dagger$ & $52.4 \pm 5.5(4) \ddagger$ \\
Case 4 & $28.0 \pm 5.8(4) \ddagger$ & $35.7 \pm 7.9(4)^{*}$ \\
Normal pyruvate oxidation & $58.1 \pm 11.5$ & $85.8 \pm 9.9$ \\
$\quad$ (16) & & \\
Controls (4) & $59.6 \pm 13.2$ & $97.3 \pm 12.0$ \\
\hline
\end{tabular}

$* \uparrow \ddagger$ Significantly different from the value for controls at $p<0.001$, $p<0.05$ and $p<0.01$, respectively. 
to the total activities of the PDH complex. In cells from the four patients with congenital lactic acidosis, the original activities of the PDH complex were significantly lower than those in control cells, but overlapped the lower values for control cells, whereas the total activities of the PDH complex, measured after in vitro activation with an excessive amount of a broad specificity protein phophatase, were within the normal range. However, the activity of the PDH complex measured after activation by the endogenous PDH phosphatase with DCA hardly increased in three of the four patients (cases 1,2, and 3) but was activated to the normal range in one patient (case 4).

As shown in Table 3 , the rates of decarboxylation of $\left[1-{ }^{14} \mathrm{C}\right]$ acetate were within the normal range in the patient with PDH deficiency and in the four patients with congenital lactic acidosis.

\section{DISCUSSION}

For establishment of a diagnosis of congenital lactic acidosis, the usual procedures are measurements of the rates of decarboxylation of $\left[1-{ }^{14} \mathrm{C}\right]$ pyruvate and $\left[3-{ }^{14} \mathrm{C}\right]$ pyruvate, the activities of enzymes involved in pyruvate metabolism, i.e. the PDH complex, pyruvate carboxylase (EC 6.4.1.1), and phosphoenol pyruvate carboxykinase (EC 4.1.1.49), and the activities of the components of the respiratory chain including cytochrome $c$ oxidase (EC 1.9.3.1) in cultured skin fibroblasts from the patients. However, in many patients with congenital lactic acidosis, the underlying deficiency cannot be found in the skin fibroblasts $(2,3)$. Three possible reasons why no defect is detectable may be considered; 1) The enzyme deficiency may not be clearly expressed in fibroblasts. 2) The deficiency may be expressed in fibroblasts, but the assay method may not be sensitive enough for its detection. 3) Lactic acidosis may be a secondary phenomenon resulting from a primary block elsewhere in metabolism (2). Therefore, it is important to develop a sensitive assay method for screening disorders of pyruvate metabolism in cultured skin fibroblasts to determine the underlying defect in patients with congenital lactic acidosis.

$\left[1-{ }^{14} \mathrm{C}\right]$ pyruvate enters the mitochondria through the mitochondrial membrane and is converted to acetyl $\mathrm{CoA}$ and ${ }^{14} \mathrm{CO}_{2}$ by the action of the PDH complex in the mitochondrial matrix (11). Therefore, a low rate of decarboxylation of $\left[1-{ }^{14} \mathrm{C}\right]$ pyruvate suggests that the aberration exists either in the $\mathrm{PDH}$ complex or in the system for transport of pyruvate through the mitochondrial membrane. Furthermore, cultured skin fibroblasts from patients with lactic acidosis due to a defect in the reoxidation of cytoplasmically generated NADH and respiratory chain defects are reported to show low rates of decarboxylation of $\left[1-{ }^{14} \mathrm{C}\right]$ pyruvate $(12,13)$. Thus, measurement of the rate of decarboxylation of $\left[1-{ }^{14} \mathrm{C}\right]$ pyruvate in cultured skin fibroblasts is useful in screening for disorders of pyruvate metabolism. However, when disorders are mild, detection of disorders of pyruvate metabolism in cultured skin fibroblasts may be very difficult. In cases of dihydrolipoyl dehydrogenase $\left(E_{3}\right)$ (EC 1.6.4.3) deficiency, the rate of decarboxylation was significantly lower than that of controls, but was $75 \%$ of the control rate (2). The rates of decarboxylation of $\left[1-{ }^{14} \mathrm{C}\right]$ pyruvate in fibroblasts from four of 20 patients with congenital lactic acidosis were also lower than those in control fibroblasts, but the upper values for these patients overlapped the lower values for control subjects. These results may be because the activity of the PDH complex appears to be regulated by a phosphorylation-dephosphorylation mechanism in human skin fibroblasts and the state of activation of this enzyme varies widely depending on metabolic conditions (14). Therefore, it is important to control this parameter in studies on PDH deficiencies. The fully activated enzyme probably furnishes the most reliable estimate of enzymatic activity. The enzyme can be activated by pretreating the skin fibroblasts for $15 \mathrm{~min}$ with DCA, an inhibitor of PDH kinase (EC 2.7.1.99), before the cells are disrupted for measurement of activity of the PDH complex (9). For use in screening for disorders of pyruvate metabolism, we also developed a sensitive assay method for measuring the rates of decarboxylation of $\left[1-{ }^{14} \mathrm{C}\right]$ pyruvate during in vitro culture of skin fibroblasts with DCA.

The rate of decarboxylation of $\left[1-{ }^{14} \mathrm{C}\right]$ pyruvate by skin fibroblasts from control subjects increased during in vitro culture in medium supplemented with $10 \mathrm{mM}$ DCA, reaching a maximum on day 3 of culture. As mentioned above, the PDH complex can be activated by pretreating the skin fibroblasts with DCA for 15 min before disrupting the cells for measurement of the activity of the PDH complex (9). However, the rate of decarboxylation of $\left[1-{ }^{14} \mathrm{C}\right]$ pyruvate did not increase until day 2 of culture.

In contrast, the rate of decarboxylation of $\left[1-{ }^{14} \mathrm{C}\right]$ pyruvate hardly increased in cells from a patient with PDH deficiency or in cells from four of 20 patients with congenital lactic acidosis of unknown cause during in vitro culture with DCA. On day 3 of culture, the values for the four patients did not overlap those of control cells and so these four patients could be clearly distinguished from control subjects. Thus, measurement of the rate of decarboxylation of $\left[1-{ }^{14} \mathrm{C}\right]$ pyruvate by skin fibroblasts cultured in medium supplemented with $10 \mathrm{mM}$ DCA for 3 days is a useful method for screening for disorders of pyruvate metabolism in cultured skin fibroblasts.

To determine the reasons for the disorders of pyruvate metabolism in cells from these four patients with congenital lactic

Table 3. Rate of decarboxylation of $\left[1-{ }^{14} \mathrm{C}\right]$ acetate in cultured skin fibroblasts from control subjects, patients with congenital lactic acidosis, and patient with PDH deficiency (mean $\pm S D)$

\begin{tabular}{cc}
\hline & $\begin{array}{c}{\left[1-{ }^{14} \mathrm{C}\right] \text { acetate decarboxylation }} \\
(\mathrm{nmol} / \mathrm{h} / \mathrm{mg} \text { protein })\end{array}$ \\
\hline PDH deficiency & $2.34 \pm 1.19(3)$ \\
Lactic acidosis & \\
Case 1 & $2.74 \pm 1.69(3)$ \\
Case 2 & $1.55 \pm 0.13(2)$ \\
Case 3 & $1.51 \pm 0.29(3)$ \\
Case 4 & $1.80 \pm 0.48(3)$ \\
Controls & $1.81 \pm 0.69(5)$ \\
\hline
\end{tabular}

Table 2. Activities of pyruvate dehydrogenase complex in cultured skin fibroblasts assayed in various conditions (mean \pm SD)

\begin{tabular}{lccc}
\hline & & \multicolumn{2}{c}{$\begin{array}{c}\text { PDH complex activity } \\
\text { (nmol/min/mg protein) }\end{array}$} \\
\cline { 2 - 4 } & Original & DCA-activated & Total \\
\hline PDH deficiency (1) & $0.27 \pm 0.17(4)^{*}$ & $0.21 \pm 0.05(3)^{*}$ & $0.42 \pm 0.06(3)^{*}$ \\
Lactic acidosis (20) & & & \\
Low pyruvate oxidation (4) & $0.39 \pm 0.33(5)^{*}$ & $0.68 \pm 0.19(4) \dagger$ & $2.04 \pm 0.24(4)$ \\
Case 1 & $0.62 \pm 0.08(2) \ddagger$ & $0.76 \pm 0.02(3) \ddagger$ & $2.40 \pm 0.69(4)$ \\
Case 2 & $0.74 \pm 0.19(3) \ddagger$ & $0.78 \pm 0.18(4) \dagger$ & $2.63 \pm 0.65(3)$ \\
Case 3 & $0.78 \pm 0.46(4) \ddagger$ & $2.43 \pm 0.41(3)$ & $2.57 \pm 0.80(3)$ \\
Case 4 & $1.65 \pm 0.67(13)$ & $2.32 \pm 0.34(8)$ & $2.50 \pm 0.64(13)$ \\
Normal pyruvate oxidation (16) & $1.44 \pm 0.46(14)$ & $2.38 \pm 0.60(4)$ & $2.41 \pm 0.59(14)$ \\
Controls & &
\end{tabular}

\footnotetext{
$* \uparrow \uparrow$ Significantly different from the value for controls at $p<0.001, p<0.01, p<0.05$, respectively.
} 
acidosis, we measured the activities of the PDH complex in various conditions. The original activities of the PDH complex were significantly lower than those of control cells, but overlapped the lower values for control cells, whereas the total activities of the $\mathrm{PDH}$ complex, measured after in vitro activation with an excess amount of a broad specificity protein phosphatase from rabbit liver, were within the normal range. During incubation with $10 \mathrm{mM}$ DCA, when the PDH complex in control cells was slightly activated by endogenous PDH phophatase, the activity of the PDH complex was activated to the normal range in cells of one patient, but was hardly increased in those of the three other patients. These results suggest that the aberration was a disorder of the mitochondrial transport system for pyruvate or dysfunction of the TCA cycle or respiratory chain in the one patient, whereas it was a disorder in the mechanism for activation of PDH, including deficiency of PDH phosphatase or a mutation of PDH itself, in the other three patients.

Fibroblasts from two patients with Leigh disease were concluded to show abnormal activation of $\mathrm{PDH}$, because their incubation with DCA did not increase the activity of the PDH complex (15). However, as shown in Table 2, measurements of only the original activity and DCA-activated activity of the PDH complex do not indicate whether the aberration was due to abnormal activation of PDH or to partial deficiency of PDH in the patients. Thus, for studies on PDH deficiencies, both the original activity and the total activity of the PDH complex must be determined by in vitro activations with both a broad specificity protein phophatase and DCA.

For determination of the disorder of pyruvate metabolism in case 4 , we measured the rate of decarboxylation of $\left[1-{ }^{14} \mathrm{C}\right]$ acetate in skin fibroblasts. The rate of decarboxylation of $\left[1-{ }^{14} \mathrm{C}\right]$ acetate, which is converted to acetyl CoA and oxidized via the TCA cycle, was within the normal range in a patient with $\mathrm{PDH}$ deficiency and the four patients with congenital lactic acidosis, and therefore the function of the TCA cycle and the activities of the components of the respiratory chain in these patients were supposed to be normal. However, in case 4, although the PDH complex showed normal total activity and a normal mechanism of activation, its original activity and the rate of decarboxylation of $\left[1-{ }^{14} \mathrm{C}\right]$ pyruvate were significantly decreased. Pyruvate enters the mitochondria by a special transport system, but acetate enters freely (11). Therefore, we speculate that the aberration in case 4 may be a disorder of the mitochondrial transport system for pyruvate, resulting in a low level of pyruvate and decrease in the in vivo activity of the PDH complex in the mitochondria. Further studies are necessary to determine the exact nature of this aberration.

\section{REFERENCES}

1. Blass JP 1983 Inborn errors of pyruvate metabolism. In: Stanbury JB, Wygaarden JB, Fredrickson DS, Goldstein JL, Brown MS (eds) The Metabolic Basis of Inherited Disease. McGraw-Hill Book Co., New York, pp 193-203

2. Robinson BH, Taylor J, Sherwood WG 1980 The genetic heterogeneity of lactic acidosis: occurrence of recognizable inborn errors of metabolism in a pediatric population with lactic acidosis. Pediatr Res 14:956-962

3. Miyabayashi S, Ito T, Narisawa K, Iinuma K, Tada K 1985 Biochemical study in 28 children with lactic acidosis in relation to Leigh's encephalomyelopathy. Eur J Pediatr 143:278-283

4. Toshima K, Kuroda Y, Naito E, Yokota I, Ito M, Watanabe T, Takeda E, Miyao M, Nonaka I 1985 Diagnosis of partial deficiency of the pyruvate dehydrogenase complex in biopsied muscle. Neurology 35:1670-1672

5. Blass JP, Avigan J, Uhlendorf BW 1970 A defect in pyruvate decarboxylase in a child with intermittent movement disorder. J Clin Invest 49:423-424

6. Toshima K, Kuroda Y, Takeda E, Watanabe T, Ito M, Naito E, Miyao M 1984 In vitro activation of the pyruvate dehydrogenase complex in human muscle by a broad specificity protein phosphatase. J Inherited Metab Dis 7:143-144

7. Blass JP, Cederbaum SD, Kark RAP 1977 Rapid diagnosis of pyruvate and ketoglutarate dehydrogenase deficiencies in platelet-enriched preparations from blood. Clin Chim Acta 75:21-30

8. Harris RA, Paxton R, Parker RA 1982 Activation of the branched chain ketoacid dehydrogenase complex by a broad specificity protein phosphatase. Biochem Biophys Res Commun 107:1497-1503

9. Sheu KFR, Hu CWC, Utter MF 1981 Pyruvate dehydrogenase complex activity in normal and deficient fibroblasts. J Clin Invest 67:1463-1471

10. Lowry OH, Rosenbrough NJ, Farr AL, Randall RJ 1951 Protein measurement with the Folin phenol reagent. J Biol Chem 193:265-275

11. Mayes PA 1985 Biologic oxidation. In: Martin DW, Mayes PA, Rodwell VW, Granner DK (eds) Harper's Review of Biochemistry, 20th ed. Lange Medical Publications, Los Altos, CA, pp 143-145

12. Robinson BH, Ward J, Goodyer P, Baudet A 1986 Respiratory chain defects in the mitochondria of cultured skin fibroblasts from three patients with lactic acidemia. J Clin Invest 77:1422-1427

13. Robinson BH 1983 Lactic acidosis, neurological deterioration and compromised cellular pyruvate oxidation due to a defect in the reoxidation of cytoplasmically generated NADH. Eur J Pediatr 140:98-101

14. Reed LJ 1974 Multienzyme complexes. Acta Chem Res 7:40-46

15. Sorbi S, Blass JP 1982 Abnormal activation of pyruvate dehydrogenase in Leigh disease fibroblasts. Neurology 32:555-558 